\title{
La casación penal: de la nomofilaquia al control de legitimidad constitucional de las sentencias
}

\author{
Recibido: 13 de abril de 2020 • Aprobado: 9 de agosto de 2020 \\ https://doi.org/10.22395/ojum.v20n42a16
}

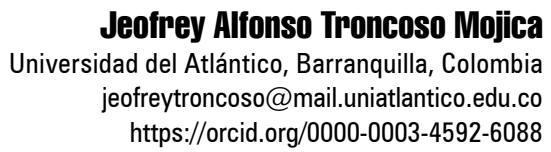

\section{RESUMEN}

El presente trabajo aborda los antecedentes de la casación penal, sus componentes teleológicos y la reforma constitucional de 1991 en Colombia. Esto con el fin de proponer, desde un enfoque constitucional, un control efectivo de las sentencias de segunda instancia que permita superar la clásica función nomofiláctica extrapolada del otrora Estado liberal surgido de la Revolución francesa sin propiciar una tercera instancia. Para desarrollar el problema de investigación, se adelantó un riguroso estudio documental, al que se le aplicó un método descriptivo y analítico a partir de los antecedentes de la casación y su naturaleza jurídico-política, los fundamentos teleológicos del recurso y su relación con el ideal de justicia que propugna el actual Estado constitucional de derecho. El estudio muestra que la función nomofiláctica de la casación cede ante la tutela efectiva de los derechos fundamentales de las partes, la reparación de los agravios infligidos y la búsqueda de un orden democrático justo. Por consiguiente, en la nueva filosofía del Estado colombiano, la casación está llamada a controlar los equívocos e inequidades de los jueces más allá de las arraigadas concepciones dogmáticas del recurso extraordinario.

Palabras clave: casación penal; recurso extraordinario; control de legitimidad; sentencia, justicia material, derechos fundamentales; nomofilaxis. 


\section{Criminal Cassation: from Nomophylax to Control of Constitutional Legitimacy of Sentences}

\section{ABSTRACT}

The present work addresses the precedents of the penal cassation, it's teleological components and the constitutional reform of 1991 in Colombia, in order to propose from a constitutional approach from a skill of contesting, focused in the effective control of the judgments of the second instance, to allow to overcome the classic extrapolated nomophylactic function of the state that emerged from the French Revolution, without propitiating the third instance. To develop the problem of the investigation there went forward a rigorous documentary the study, to which a descriptive and analytical method was applied to, from the precedents of the cassation and its juridical-political nature, the teleological essentials of the resource and its relation with the ideal of justice that supports the current social state based on the rule of law. The study shows that the nomophylactic function of the cassation yields before the effective tutelage of the fundamental rights of the parts, the repair of the inflicted grievance, and the search of a just democratic order. Consequently, in the new philosophy of the Colombian State the cassation is named to control the ambiguities and inequities of the judges, beyond the deeprooted dogmatic conceptions of the extraordinary resource.

Keywords: criminal cassation; extraordinary appeal; legitimacy check; judgment; effective justice; fundamental rights; nomophilactis function. 


\section{INTRODUCCIÓN}

Este artículo es el resultado de la investigación: La casación como control de legitimidad de las sentencias de segunda instancia en Colombia (Troncoso, 2017), con la cual adquirí el grado de magíster en Derecho por la Universidad Sergio Arboleda de Colombia. A diferencia de la investigación mencionada, el presente artículo se centrará en el estudio de la casación en el derecho penal.

En Colombia el recurso de casación fue concebido desde el año 1886-siguiendo el formalismo jurídico imperante- como medio de impugnación extraordinario dirigido a quebrar o anular las sentencias de segunda instancia, en materia penal y civil. Este hecho se presenta cuando son sentencias violatorias de la ley sustancial o presentan ciertos problemas de anomia o antinomia que requerían la unificación de conceptos por la jurisprudencia para la uniforme aplicación de las normas jurídicas. Con los desarrollos legales posteriores, en materia criminal, el recurso se extendió igualmente a dejar sin valor jurídico la sentencia de segundo grado por ser violatoria de normas procesales de efectos sustanciales, o por desconocer las reglas sobre garantías o estructura que exhortan al debido enjuiciamiento penal.

En la Ley 600 (2000) y la Ley 906 (2004), de los actuales códigos de procedimiento penal, persiste la función preponderantemente nomofiláctica del recurso de casación en la que siguiendo el positivismo jurídico -kelseniano o el de Hart- se privilegia la defensa del ordenamiento jurídico mediante la unificación de la jurisprudencia. Este privilegio se presenta por encima de la protección material de los derechos fundamentales de las partes del proceso. Si bien no puede desconocerse ciertos avances que, en materia de garantías del debido proceso, ha significado en nuestro medio la progresiva postura de la jurisprudencia y el desarrollo legislativo del recurso, ello no resulta suficiente mientras persista la concepción legalista de la justicia y se ubique en un plano accesorio la finalidad axiológica de la casación.

Partiendo de esa función nomofiláctica, del recurso de la casación, se establecen por vía jurisprudencial varias técnicas procedimentales, estereotipadas en la práctica para blindar de seguridad jurídica las sentencias de segunda instancia. Esto bajo la condición de que el recurrente en casación debe argumentativamente derruir las presunciones de legalidad y de acierto que abrigan tales decisiones judiciales. De esta manera, se subvaloran caros derechos y libertades que subyacen como derecho material superlativo frente al argumento de intangibilidad de la sentencia del Tribunal.

Además de cada cargo específico, la jurisprudencia fija varios condicionamientos de procedibilidad del recurso, a manera de tecnicismos inexorables, sin los cuales resulta inadmisible el estudio de los cargos (justos o no) propuestos por el recurrente en casación o, en el mejor de los casos, la admisión de la demanda queda sujeta a la discrecionalidad de la Corte de Casación. Todas estas restricciones meramente formales o instrumentales 
conllevan a que en Colombia solo se posibilite el estudio de la casación penal en un promedio del cinco por ciento de las demandas presentadas por los reclamantes de justicia: llámese acusado por conducto de su defensor, apoderado de víctima o representación institucional.

En la actualidad la perspectiva y teleología del recurso de casación revisten de vital trascendencia en Colombia. Esto se debe a la reciente enmienda de la Constitución Política en la que -mientras se tira por la borda las conquistas humanísticas de Beccaria (2003) - se autoriza la prisión perpetua por crímenes graves contra menores de edad, ya que ni la consulta sobre tan drástico castigo (control automático ante el superior jerárquico) ni la revisión diferida (luego de veinticinco años de prisión) para evaluar la resocialización, servirán como remedios procesales eficaces para enmendar los errores de justicia cometidos por los tribunales en segunda instancia.

En consecuencia, la garantía constitucional de acceder efectivamente a la justicia a través del recurso de casación penal -como el último remedio para revisar y enmendar los errores judiciales- resulta en alto grado restringida. En esa medida, el mero control de legalidad de la decisión pregonado por la ley y desarrollado por la jurisprudencia es deficitario frente a la efectividad de los derechos fundamentales a la libertad, la dignidad, la verdad, la reparación (Sentencia C-753/13, 2013), la justicia y el debido proceso de los sujetos involucrados en el juicio. Por ello, la presente investigación tiene por finalidad el estudio de la casación penal como medio de control de legitimidad para la protección de las garantías y derechos fundamentales de las partes o sujetos procesales, bajo la siguiente pregunta:

¿De qué manera puede concebirse la casación penal como control de legitimidad para la protección efectiva de los derechos y garantías fundamentales de las partes?

El objetivo general de este estudio consistirá en proponer un enfoque de la casación focalizada al control efectivo de legitimidad de las sentencias de segunda instancia en la aplicación de los derechos y garantías fundamentales de las partes.

Este trabajo se trazó sobre tres objetivos específicos que serán desarrollados en los respectivos capítulos. En primer lugar, se examinarán los antecedentes de la casación y su naturaleza jurídico-política. En segundo lugar, se buscará establecer los fundamentos teleológicos de la casación, su relación con el ideal de justicia y de protección de derechos objetivos. En último lugar, se articulará los fines de la casación con las acciones constitucionales protectoras de derechos y garantías fundamentales.

Tomando como referente el problema de investigación, se analiza si a la luz del Estado social de derecho, adoptado por Colombia desde el año 1991, y del derecho procesal contemporáneo se puede seguir concibiendo la casación como un recurso extraordinario para la aplicación uniforme de la ley sustancial o si, por el contrario, puede proyectarse como un medio de control constitucional dirigido a la 
protección efectiva de los derechos y garantías fundamentales de los sujetos que se someten al escrutinio del proceso judicial.

En la presente investigación se acudió a distintas fuentes bibliográficas de autores nacionales y extranjeros, a sentencias de nuestros altos tribunales de la justicia, legislaciones históricas y actualizadas, revistas jurídicas, artículos, documentos de archivo, entre otras bases del conocimiento detalladas al final del trabajo. Este material fue debidamente analizado y delimitado, en cuanto a su pertinencia con el tema.

\section{ANTECEDENTES DE LA CASACIÓN Y SU NATURALEZA}

\subsection{Origen de la casación}

El vocablo casación proviene del latín casso, as, are y del vocablo francés casser que significa romper, quebrar o anular. Para Calamandrei (1945a) no existe un referente histórico completo sobre el origen de la casación, pues hay quienes la remontan al Sanedrín del pueblo hebreo o al Areópago de la Antigua Grecia. Sin embargo, en los estados modernos es el resultado de la conjunción de dos instituciones: una jurídico-política (la Corte de Casación) y otra de derecho procesal (el recurso de casación), proveniente de la extrapolación de institutos creados con la Revolución francesa. Pese a ello, Calamandrei (1945a) pone de presente ciertos antecedentes de la casación en el derecho italiano y germánico, como fueron la tercera instancia y la querella de nulidad contra las sentencias.

Calamandrei (1945a) consideraba que el nacimiento de la casación se remonta al conflicto del monarca con los parlamentos (tribunales judiciales de la época) para sostener el absolutismo. Esto se debe a que los tribunales -como órganos judiciales- empezaron a ejercer una especie de control constitucional sobre el poder soberano, este poder contrarrestaba tales decisiones judiciales a través de la suspensión, modificación o eliminación de los procesos, o sobreponiendo su poder jurisdiccional sobre el de los jueces con el pretexto de la buena marcha de la justicia (Calamandrei, 1945a, pp. 317-318), a través de lo que se denominó Conseil des parties (Calamandrei, 1945b, p. 17). También se tiene como antecedente remoto la Ordenanza de Blois del año 1579, que facultó a los interesados para recurrir ante el rey los fallos judiciales que desconocieran sus ordenanzas (Devis, 1966, p. 679).

A partir de la Revolución francesa surge la institución de la casación como un recurso dirigido a proteger la eficacia normativa otorgada a la ley, por cuenta de la desconfianza que mantenía la burguesía revolucionaria en el poder judicial de la aristocracia, quienes en el ancien régimen traicionaron la confianza depositada por la monarquía (Martínez, 2010, p. 16). Por las razones expuestas, resulta innegable el carácter eminentemente político con que surge y fue concebida la casación en el derecho público. 
Con ese enfoque del recurso, dirigido a la salvaguardia de la ley o norma sustancial para mantener la estabilidad institucional, tanto el legislador como la jurisprudencia mantienen el paradigma posrevolucionario de defensa de la ley, catapultado por Robespierre en el célebre discurso del 25 de mayo de 1790 (Rosanvallon, 2015, p. 45). Allí el francés pregonó que los tribunales de justicia estaban institucionalizados para resolver conflictos entre los ciudadanos, mientras que el Tribunal de Casación-como órgano sedentario- tenía como propósito controlar las decisiones en las cuales se violaran las normas legales y la separación de los poderes, especialmente evitar la intromisión del poder judicial en el poder legislativo. Esta proclamación fue convertida meses más tarde en una norma procesal, a través del decreto de noviembre 27-1 de diciembre de 1790, de la Asamblea Constituyente francesa (Calamandrei, 1945b, pp. 38-40).

A finales del siglo XIX y comienzos del siglo XX, al atenuarse el rigor de las ideas revolucionarias, el Tribunal de Casación francés (igual que los tribunales de Italia, Bélgica, Holanda, Luxemburgo, Grecia y de España) se transformó en un modelo de corte de casación, cuya misión no sería la ideología política de la desconfianza en los jueces y contar con un mecanismo para la anulación de sus fallos. Para Cappelletti (2007, p. 37), con la potestad de interpretación de puntos derecho, otorgada a los jueces por la ley fundamental del 1 de abril de 1837, las funciones del alto tribunal se dirigen a la interpretación suprema de las normas legales para unificar el juicio hermenéutico realizado por los jueces y de esta manera sus decisiones adquieren una dimensión jurisprudencial.

Para la misma época, el recurso de casación penal y civil fue instituido en Italia con dos funciones diferenciables, ajenas al reexamen de los hechos de la relación jurídico-procesal. La primera para revisar el juicio normativo efectuado por el juez inferior y, una vez casada su sentencia, él mismo produzca una nueva resolución de fondo susceptible de otro recurso de casación, función que implicaba la conexión entre un interés general (observancia de la ley) y un interés individual (fin perseguido por las partes). La segunda función consistía en examinar el juicio de actividad desplegado en el inicio, el desarrollo y el final del proceso, para dejar sin efectos a las sentencias viciadas de nulidad insubsanable (Chiovenda, 1922, pp. 473, 474).

Esa caracterización con que surgió hace más de dos siglos el recurso de casación, como control extraordinario de legalidad, ha llevado a que en la práctica de nuestros procedimientos contemporáneos se mantenga el paradigma de que la esencia de la casación es la nomofilaquia, esto es, asegurar la salvaguarda de la ley sustancial bajo el arquetipo de la unificación de la jurisprudencia (Martínez, 2010, p. 15). No obstante, en segundo orden, de manera progresiva se concibieron como causales de casación los vicios de actividad en el razonamiento de la sentencia y luego los errores o vicios del procedimiento (Calamandrei, 1945a, pp. 53, 177-178); y, en tercer orden, la reparación 
del daño padecido con la sentencia recurrida. Lo cual enfoca el recurso a partir de las presunciones de legalidad y de acierto de la sentencia.

La Constitución Política de Colombia (1886) asignó en su artículo 151 a la Corte Suprema de Justicia la competencia para conocer del recurso de casación. Al inicio la casación se estableció en materia civil y de manera excepcional para revisar la pena capital o de muerte. Sin embargo, el recurso extraordinario para las causas criminales desaparece en el año 1910 con la abolición de la pena de muerte (Tolosa, 2005, p. 61). Posteriormente, en el artículo 3 de la Ley 78 (1923) se reestablece el recurso de casación por ser la sentencia de segundo grado violatoria de la ley penal; por errónea interpretación o por aplicación indebida; por vicios de nulidad sustancial; por falta de competencia; o por incongruencia entre la sentencia y los cargos o el veredicto del jurado.

Como se advierte, desde su consagración, la casación penal ha sido concebida en Colombia como un recurso extraordinario que busca la preservación del derecho objetivo (mirado como norma jurídica), la unificación de los conceptos jurídicos y la reparación del daño infligido por una sentencia de segundo grado. Este enfoque se posibilitó sobre el paradigma de obedecimiento de la ley y de la unificación de la jurisprudencia, para disuadir a la aplicación de normas legales desprovistas de valoraciones ético-sociales, propio del formalismo jurídico de la jurisprudencia de conceptos que imperó en el siglo xix (Bobbio, 2007, p. 32).

\subsection{Naturaleza de la casación}

Sin duda alguna, la naturaleza nomofiláctica del recurso extraordinario de casación proviene del pensamiento separatista de poderes promulgado por Montesquieu (1806) en su obra maestra, cuando lacónicamente sostenía que, de los tres poderes públicos, el de juzgar "es en cierta manera nulo" y, a raíz de ello, consideraba que el juez era un ser inanimado sin derecho a moderar su fuerza ni su rigor, por ser la boca por donde hablaba la ley (Montesquieu, 1906, pp. 233-237). Luego de la Revolución francesa, los antecedentes históricos antes reseñados evidencian la naturaleza político-social con la cual nace el recurso para proteger la estabilidad institucional.

En Colombia el recurso extraordinario de casación se dirige a la protección de la ley sustancial ante la presencia de vicios in iudicando, esto es, errores de selección, subsunción o de interpretación normativa; o de vicios facti in iudicando, esto es, errores de hecho en el juicio normativo. Estos vicios implican la violación directa de la norma de derecho objetivo, en el primer caso, o indirecta, en el segundo caso (Auto 16054, 2000). También es viable - de modo excepcional- la procedencia del recurso ante la existencia de vicios in procedendo, configurados en irregularidades de estructura o de garantías debidas a las personas, provenientes del desconocimiento de subprincipios y reglas técnicas trascedentes del debido proceso (Auto 33170, 2010). 
En la primera causal de casación antes referida, el vicio se genera por la violación directa de la norma (sustantiva o procesal de contenido sustancial) por falta de aplicación, aplicación indebida e interpretación errónea de la norma positiva. En este sentido, no está permitido discutir los enunciados fácticos fijados en la sentencia, sino los errores de selección, de subsunción normativa o de correcta interpretación de la regla sustancial, que eventualmente afectarían la decisión judicial por ser lesiva del principio de legalidad y de la presunción de acierto de la sentencia.

En la violación indirecta (facti in iudicando), en cambio, se busca que el Tribunal de Casación reexamine los hechos fijados en la sentencia y su correspondencia con las pruebas incorporadas, que debieron ingresarse al proceso o excluirse. Esto tiene ocurrencia frente a errores, de hecho o de derecho, en la apreciación o aducción de las pruebas (Tolosa, 2005, p. 362) para la aplicación unificada de la ley sustancial (derecho objetivo). Dentro de los errores de hecho la jurisprudencia ha caracterizado el falso juicio de existencia, el falso juicio de identidad y el falso raciocinio; y respecto de los errores de derecho los ha caracterizado en falso juicio de legalidad y falso juicio de convicción (Auto 36053, 2011).

En ambos casos, la consecuencia jurídica que se deriva del quiebre de la sentencia impugnada es que el Tribunal de Casación actúa como juez de segunda instancia y, por ello, dicta un nuevo fallo (de reemplazo o sustitutivo) en el que asume el conocimiento del recurso de apelación formulado contra la sentencia de primer grado. En este sentido, hace las declaraciones que en derecho correspondan para salvaguardar la eficacia de la norma sustancial infringida por vía directa o indirecta.

La segunda tipología de vicios en casación se presenta cuando la sentencia es dictada con grave lesión del debido proceso. De acuerdo con la jurisprudencia, esta causal tiene lugar, bien sea porque se desconocieron las reglas técnicas sobre la estructura orgánica de la actuación o porque se desquiciaron las garantías mínimas de las partes. Garantías como los derechos de publicidad, de defensa y de controversia, la regla técnica de la congruencia de las sentencias, la prohibición de la reforma en perjuicio, entre otras (Ramírez, 2011, p. 504).

La jurisprudencia y la doctrina coinciden en afirmar que, en el primer caso se trata de vicios de estructura y en el segundo de vicios de garantías. En materia penal, de constatarse la existencia de un vicio que lesione la validez del proceso, la Corte Suprema de Justicia ordenará rehacer la actuación a partir del acto procesal que origina la nulidad. Sin embargo, esto no sucede cuando el vicio no sea propiamente de actividad, como acontece en la indebida motivación del fallo atacado (Auto 30073, 2011), pues ante esta eventualidad, que fractura las garantías de publicidad y contradicción, el Tribunal de Casación simplemente profiere una sentencia sustitutiva. 
Muchas son las críticas hacia el recurso de casación por el reexamen de los hechos y, por supuesto, contra la dimensión dikelógica que asumen ciertos tribunales de casación en la resolución del caso concreto e interpretación del derecho (como jueces de cierre). Los críticos reclaman un modelo de casación pura -en la idea de Calamandrei- dirigido a la función nomofiláctica (control de legalidad) de la decisión judicial y la uniformidad de la jurisprudencia, con el propósito de lograr precedentes de carácter persuasivo, validos de uniformidad sincrónica de la norma, pero con variaciones razonables (Taruffo, 2005, pp. 164-165).

Por ello, la caracterización de la casación, bien como recurso extraordinario o como control de legitimidad constitucional de la decisión, tendrá enormes repercusiones teórico-prácticas y político-sociales. En el primer caso, la justicia sería estrictamente rogada, esto es, se exigiría del recurrente la carga procesal de acreditar con argumentos -en la demanda- la existencia del error directo o indirecto en la selección de la norma sustantiva. Por otro lado, el control de legitimidad casacional deberá orientarse a la arquitectura axiológica del modelo de Estado, con lo cual, los tecnicismos exigidos al recurrente deben ceder para permitir el decreto oficioso de la causal constatada por la Corte. El calificativo de "control de legitimidad de las providencias" a través de la Corte de casación, no es novedoso, fue empleado en la década de los setenta por Cappelletti (1974, p. 562).

\subsection{La casación en la legislación colombiana}

A través de la Ley 61 (1886) Colombia fijó el paradigma nomofiláctico del recurso, propio del entonces positivismo jurídico, conforme al cual el fin basilar de la casación era la unificación de la jurisprudencia, enmendar los agravios causados a las partes y la aplicación debida de las normas legales. Esta finalidad es reiterada sucesivamente a través del artículo 3 de la Ley 78 (1923), la Ley 118 (1931), el artículo 33 de la Ley 105 (1931) del Código Judicial, el Decreto 1345 (1970) en el artículo 573, el Decreto 409 (1971) en el artículo 580, el Decreto 50 (1987) en el artículo 226 y el Decreto 2700 (1991) en el artículo 220.

Este último Código Procesal Penal (1991), alineado con la recién promulgada Constitución Política, por primera vez asigna una finalidad y enfoque valorativo al medio extraordinario de impugnación: "la efectividad del derecho material y de las garantías debidas a las personas que intervienen en la actuación penal, la reparación de los agravios inferidos a las partes por la sentencia recurrida, y la unificación de la jurisprudencia nacional" (1991, art. 219). Esta teleología sirvió de sustento para implementar por primera vez la figura de la casación discrecional, en clave del desarrollo de la jurisprudencia y la protección efectiva de los derechos fundamentales (art. 218). Finalidad reiterada en el Código Procesal Penal (2000) que lo sucedió (Ley 600, 2000, art. 206). 
No obstante, esa perspectiva de la casación como recurso extraordinario para la protección del derecho objetivo (derecho material y garantías en el Código de 1991), ha sido actualizada por las nuevas axiologías constitucionales de finales del siglo XX y, con mayor fuerza, a comienzos del presente milenio. Inicialmente de manera muy discreta y excepcional por la jurisprudencia (Sentencia 10094/97, 1997), para la protección del derecho fundamental al debido proceso. De esta manera, ha dado lugar a avances procesales y probatorios significativos en cuanto a la eficacia de los derechos subjetivos por encima de las prescripciones y descripciones normativas que, no en pocos casos, sirven de barrera para la tutela judicial efectiva. Todo esto, sin que tales progresos puedan equipararse a un verdadero control de legitimidad de la decisión.

Efectivamente, si bien la jurisprudencia inició una evolución en cuanto al alcance del recurso de casación, orientándolo a la preservación de derechos fundamentales y a la efectividad del derecho material -como indicó el Código Procesal de 1991-, lo cierto es que la Corte Suprema de Justicia estableció cortapisas procedimentales basada en pronunciamientos anteriores. Estos, por encima de reglas de admisibilidad garantes de un naciente control de legitimidad constitucional, revelan ante todo el carácter restringido que permanece en el recurso: "este medio de impugnación excepcional sólo [sic] se justifica por la urgencia de proteger derechos fundamentales conculcados, si el daño se pone en evidencia con la sola indicación descriptiva del escrito de sustentación" (Auto 16776, 2000).

Por esta razón, la admisión de las demandas de casación por vulneración de derechos fundamentales no opera como un verdadero control de legitimidad constitucional, pues la Corte Suprema de Justicia exige que, desde la misma demanda, además del derecho fundamental presuntamente lesionado, se especifique el medio que lo protegía o garantizaba y la manera cómo fue desconocido o conculcado. Es más, en expresión de la Corte, para la admisión del recurso el demandante tiene la carga procesal de "indicar al menos sucintamente en que consistió la violación y su incidencia negativa en la garantía, que conllevare mengua o imposibilidad de gozar o ejercer el derecho fundamental" (Auto 15948, 2000).

Con la Ley 906 del Código de Procedimiento Penal (2004) la finalidad del recurso de casación varía sustancialmente, al dejar de cumplir una función exclusivamente nomofiláctica y protectora de garantías, para convertirse en un medio de control constitucional de la decisión judicial. De ahí que dicho código procesal no diferencia la casación ordinaria de la discrecional a la cual aludían las legislaciones anteriores. Por ello, en criterio inicial de la Corte, la admisión de la demanda de casación solo exigía verificar la finalidad del recurso, según la posición del recurrente y la índole de la controversia planteada, sin condicionarla a los requisitos técnico-formales de la demanda ni a nuevas valoraciones de estos en el fallo. De esta manera, se mantiene la potestad oficiosa por violación del debido proceso (Auto 24322, 2005). 
De tal manera, una vez admitido el recurso ya no es posible inhibirse de emitir un pronunciamiento de fondo y pretextar defectos de forma (Auto 20666, 2005), como en el pasado acontecía en la sentencia que resolvía la casación.

No obstante, vale advertir que la línea jurisprudencial referida a la admisión de la demanda de casación con prescindencia de requisitos lógico-formales, planteada por la Corte Suprema de Justicia a partir del actual Código Procesal Penal de 2004 (Auto 24322, 2005), no ha sido del todo consistente. Al punto de regresar a los viejos formulismos técnico-formales que por más de un siglo restringieron el recurso, los cuales hoy se anteponen como condición de admisibilidad:

quien acude al mismo debe ceñirse a determinados requerimientos sistemáticos basados en la razón y en la lógica argumentativa, atinentes a la observancia de coherencia, precisión y claridad en el desarrollo de cada uno de los reparos efectuados, y desarrollarlos conforme a las causales de procedencia. (Auto 36053, 2011)

De lo expuesto, se infiere que en los últimos treinta años el legislador ha cambiado la filosofía del recurso. En otras palabras, ha propugnado la defensa de los derechos fundamentales y ha desplazado a segundo plano el paradigma del recurso extraordinario de casación -como medio para impugnar la preservación de la norma positiva-, para situarlo en un control constitucional y legal de las sentencias de segundo grado cuando estas afectan derechos o garantías fundamentales. Aunque el desarrollo jurisprudencial del recurso no ha sido el más afortunado a tales fines axiológicos, pues además de restringirlo a medio de impugnación extraordinario para derruir la doble presunción del fallo y de imponer al recurrente cargas de idoneidad formal y sustancial, en la práctica le otorga carácter discrecional a su admisión.

\section{FUNDAMENTOS TELEOLÓGICOS DE LA CASACIÓN}

\subsection{Función nomofiláctica del recurso extraordinario}

En los primeros años de vigencia de la Constitución Política (1991), la casación fue concebida como un recurso extraordinario con el argumento de no constituir una tercera instancia. Por ello, su admisión requería del cumplimiento exacto de ciertos requisitos lógico-formales fijados por la jurisprudencia, bajo el axioma del modelo unitario del Estado colombiano y la función político-jurídica asignada a la casación como un instrumento para lograr la certeza jurídica en el plano de las decisiones judiciales (Sentencia C-215/94, 1994).

En ese sentido, la Corte Constitucional, con ciertos rezagos del superado Estado liberal, al analizar en sus inicios la finalidad de la casación, exaltaba su naturaleza nomofiláctica señalando que el legislador buscaba la "prevalencia del Estado de derecho, el imperio de la ley, la realización del derecho sustancial y la unificación de la jurisprudencia nacional" (Sentencia C-140/95, 1995). Por lo tanto, la Corte Suprema 
de Justicia debía ejercer sus funciones de tribunal de casación solo en aquellos casos taxativamente consagrados en los respetivos ordenamientos procesales.

Como se aprecia, la jurisprudencia constitucional, apegada a la tradición del recurso -en la concepción de Calamandrei (1945a)-, determinó que la casación era un juicio de legalidad extraordinario contra la sentencia por errores en la aplicación del derecho sustancial. En este sentido, tomaba como apéndice la violación del debido proceso. Con la entrada del nuevo milenio, la jurisprudencia aún sostenía el fundamento nomofiláctico de la casación "más de orden sistémico, para proteger la coherencia del ordenamiento y la aplicación del derecho objetivo" (Sentencia C-1065/00, 2000).

El inconveniente de esta orientación ontológica y diacrónica de la casación, dada desde la jurisprudencia de los altos tribunales de justicia, es que desatendía los paradigmas valorativos formulados por el nuevo Estado constitucional de derecho, donde los derechos fundamentales de las personas limitan la otrora aplicación ciega de la ley en los términos formulados por el positivismo jurídico (Ferrajoli, 2004, p. 26). De esta manera, la interpretación de las normas jurídicas no se encierra al significado estricto de su texto (derecho objetivo-formal), sino que se exige, además, atender el contenido teleológico que fundamenta su creación (subjetivo-axiológica).

En efecto, la transición del Estado liberal de derecho-cuyo fundamento normativo es la ley-, hacia el Estado social de derecho -donde la carta política es la fuente esencial del derecho-, implica reconducir el discurso de la aplicación estricta de la ley a un nuevo paradigma. En este, de manera ontológica, la Constitución es la norma superior de aplicación directa y obligatoria que irradia el ordenamiento jurídico positivo y se superpone a toda regla de derecho que desatienda sus cometidos (Sentencia C-820/06, 2006). Por contera, la nomofilaquia del recurso de casación se encuentra rezagada al plano estrictamente hermenéutico. En este sentido, cede su importancia a las garantías y derechos fundamentales de las personas vinculadas al proceso.

Con tal línea de pensamiento, era insostenible seguir atribuyendo a la casación una dimensión preferentemente normológica afianzada en el paradigma político-jurídico de la defensa del principio de legalidad, bajo el inveterado discurso de la uniformidad de la jurisprudencia. Además, con evidente desconocimiento de los derechos fundamentales de las personas (Constitución Política, 1991, art. 2, 86, 93); del valor supremo de la justicia dentro de un marco jurídico justo (preámbulo); de la tutela judicial efectiva (Constitución Política, 1991, art. 29, 228, 254); y de la naturaleza deóntica de la Corte Suprema de Justicia como tribunal constitucional, de cierre de la justicia ordinaria, pero igualmente con funciones de tribunal de casación (Constitución Política, 1991, art. $2,86,234,235)$. 


\subsection{La casación y el ideal de justicia}

Indudablemente el mayor avance y desarrollo de los derechos fundamentales en el plano jurídico ha sido la constitucionalización del derecho mediante las normas sustantivas y procesales. Esto se debe a que la Constitución incorporó preceptos y enunció valores y postulados con incidencia significativa para la determinación, orientación y alcance del derecho (Sentencia C-038/95, 1995), ajenos al voluntarismo estatal propio del Estado liberal de derecho. A partir de tal referente, la comprensión e integración del derecho se alinea tendencialmente a la protección de derechos del ser humano -bajo el axioma pro homine-y de contera a la realización de la justicia material (Goldschmidt, 1987, p. 337).

Con la entrada del presente milenio, la Corte Constitucional comienza a proyectar una dimensión dikelógica de la casación, aunque sin afianzar del todo su contenido de justicia. En efecto, luego de citar varios autores -en el obiter dictum de la Sentencia C-252/01 (2001) - la Corte se refirió a la finalidad de la casación penal en los siguientes términos:

Todas las concepciones, [... parten de considerarla como un "remedio extraordinario" (Giaturco) para remover condenas injustas y, por consiguiente, convergen a fines idénticos, que no son otros que los de corregir las desviaciones legales del juicio, bajo el valor primordial de alcanzar la protección de los derechos fundamentales de los sujetos pasivos del ius puniendi y la búsqueda de uniformidad jurisprudencial. (Sentencia C-252/01, 2001)

Sobre este punto, Roxin en Moreno (2015, p. 75) destaca la antigua discusión doctrinal de considerar si la finalidad del recurso de casación es el aseguramiento de la unidad del derecho (nomofilaquia) o si es la realización de la justicia al caso concreto (dimensión dikelógica) o si, en cambio, se trata de una postura mixta que lleva imbricada ambos fines legítimos. Al respecto, resulta más aventurada la postura de Bacigalupo (1994, p. 48), para quien la casación -como cualquier recurso- debe direccionarse a la protección jurídica contra toda arbitrariedad judicial. Criterios a partir de los cuales, se reelabora la función de la casación para dirigirla al ideal de justicia, pregonado en el Estado constitucional de derecho.

Por las razones anteriores, en cualquier Estado donde se presente una constitución viviente sujeta al sincronismo de las transformaciones socio-políticas, y, no en pocos casos, a los intereses sórdidos de quienes representan el interés de la sociedad (Ackerman, 2011, p. 107), son los tribunales de casación los llamados a corregir proactivamente tanto las lagunas y antinomias generadas por la actividad legislativa, como las arbitrariedades cometidas por los jueces al resolver los conflictos sometidos a su conocimiento. Todo esto, más allá del perenne e infundado temor de transitar por las fronteras de una tercera instancia, según la constante crítica despreciativa 
que postulan los acérrimos defensores del modelo nomofilaquio de Calamandrei, imperante en los albores de los siglos xix y xx.

En Colombia, el recurso de casación se encuentra sujeto a un amplio margen de discrecionalidad de la Corte, que va desde la selección de la demanda hasta la creación de las reglas lógico-formales de admisibilidad, por lo cual no siempre se cumple con sus fines ni el ideal de justicia que demanda el Estado constitucional. A raíz de ello, solo un promedio del cinco por ciento de los recursos presentados termina con una sentencia representativa del juicio de legitimidad. Esto se debe a que los autos interlocutorios de inadmisión, además de revelar el carácter discrecional en la selección de casos y la repetibilidad de formulismos limitativos de la tutela judicial efectiva, comportan cierta displicencia por la efectiva realización de los derechos fundamentales al debido proceso, a la libertad, la dignidad, la verdad, la reparación y la justicia.

En verdad, dentro de las reglas técnicas establecidas por la Corte Suprema para la admisibilidad del recurso de casación, además de los requisitos lógico-formales de la demanda, se encuentra la idoneidad sustancial. Este concepto fue empleado en el año 1982 por la Sala de Casación Penal y aludía a la prohibición de contradicción de los cargos de la demanda (Gaceta 2408, pp. 416-418). Veinte años después la jurisprudencia retoma dicha regla, reiterándola en el año 2007, para referirse a la correspondencia que debía existir entre la realidad procesal y los cargos formulados en el recurso (Auto 28387, 2007).

En el año 2011, el concepto de idoneidad sustancial da un viraje en cuanto al juicio de admisibilidad de la demanda de casación. La jurisprudencia parte de que la idoneidad formal guarda relación con el cumplimiento de las exigencias de claridad, concreción y debida fundamentación requeridas por la ley y la lógica de la causal invocada. Por otro lado, la idoneidad sustancial se dirige a la realización de los fines del recurso en los términos consagrados por normatividad procesal (Auto 34948, 2011). En la actualidad, la Corte entiende por idoneidad sustancial la acreditación de las reglas de técnica propias de la casación, mediante argumentos lógicos, coherentes y claros que permitan inferir la posible ocurrencia de errores de juicio o de procedimiento de la sentencia recurrida (Auto AP-293, 2020).

\subsection{La casación y los derechos fundamentales}

En el año 2005, la Corte Suprema de Justicia da un giro copernicano, frente a la concepción política que diacrónicamente encausó por más de un siglo la casación como un recurso extraordinario. Para ello, redirecciona su postura nomológica a una dimensión ius filosófica del instituto, guiada por la nueva axiología constitucional en materia de protección de los derechos fundamentales: "hoy en día la ley solo puede tener sentido en la medida en que sus fórmulas realicen los valores y principios del 
texto Superior y los tratados internacionales sobre derechos humanos que conforman el bloque de constitucionalidad" (Auto 24026, 2005).

La citada jurisprudencia expresó que, a partir de la carta de derechos de 1991, la interpretación del derecho dejó de ser un problema de mera lógica para convertirse en una comprensión axiológica, donde se realicen los valores y los principios contenidos en textos constitucionales y convencionales sobre derechos humanos que integran el bloque de constitucionalidad. De ahí que el recurso extraordinario de casación ya no se pueda concebir bajo el paradigma desde, por y para las causales, sino más bien: desde sus fines constitucionales. De esta manera, adquiere una dimensión axiológica, ausente en la Constitución de 1886, vinculada con los propósitos del proceso penal y sobre el ideal de justicia material trazado por el nuevo modelo de Estado constitucional, permeado por su concepción antropocéntrica.

Como bien se observa, la Sala de Casación Penal de la Corte Suprema de Justicia asume un papel sin precedentes sobre el sentido y alcance del recurso extraordinario. En este sentido, privilegia la defensa de los derechos fundamentales, como valor supremo del nuevo modelo de Estado. A partir de esta evolución paradigmática, tanto el trámite como la resolución del recurso sufrieron profundas transformaciones, al punto que los errores de técnica casacional -que otrora impedían la tutela judicial efectiva del derecho en litigio- fueron superándose en pocos casos. Esto para dar lugar a decisiones que, pese a estar fundadas en la aplicación directa de la ley, en el fondo conllevaron a un reexamen oficioso de las causales de la demanda en procura de la justicia material, solo para citar un caso (Auto 45.008, 2015).

A pesar de lo anterior, tal ideología de la Corte no ha sido consistente en la praxis judicial, pues pese a reconocer el valor supremo de los derechos y garantías fundamentales de los sujetos procesales (acusado y víctima), el tratamiento de recurso extraordinario le impone a la casación condicionamientos de admisibilidad. Estas son impuestas a través de ciertas reglas técnicas -entre ellas la de idoneidad sustancial- que impiden el acceso efectivo a la justicia, con la idea obcecada de la doble presunción de legalidad y de acierto de los fallos de segundo grado (Auto AP-648, 2020). Entendida la tutela judicial efectiva, no como el mero derecho a la resolución oportuna del caso con la garantía de doble conformidad de la decisión, sino bajo el supuesto de que esta irradie la verdad y la justicia, previo un debido proceso.

En palabras de la Corte Constitucional, el nuevo modelo político de Estado generó importantes repercusiones en la visión del recurso extraordinario de casación, sustituyendo la concepción formalista de la administración de justicia -vinculada al simple propósito del respeto a la legalidad-, por un espectro más amplio y garantista en el que la justicia se alinea al efectivo amparo de los derechos fundamentales de los asociados: 
En estos términos, pese a que el recurso extraordinario de casación sea una antigua institución jurídica, ésta [sic] ha evolucionado notablemente para enfrentar los nuevos retos y realidades que impone esta nueva percepción del derecho, y particularmente del sentido de la ley ante el reconocimiento de la Constitución como verdadera norma jurídica. (Sentencia C-372/11, 2011)

En ese orden de ideas, la jurisprudencia colombiana avanza de una concepción netamente positivista -basada en el carácter nomológico de la casación- a una visión dikelógica e integradora del derecho, donde se privilegian la superioridad de la Constitución (Goldschmidt, 1987, p. 341) y de los derechos fundamentales. De esta manera, se supera el dogma liberal-estatista de la fuerza absoluta de la ley para dar lugar privilegiado a las normas constitucionales de garantías, dirigidas a la tutela eficaz de las libertades y derechos individuales que delimitan la potestad de acción de los poderes públicos (Fioravanti, 2000, p. 129).

\section{LA CASACIÓN Y LA CONSTITUCIÓN DE 1991}

\subsection{Los derechos subjetivos y el principio de legalidad}

Un pilar del Estado constitucional de derecho son los derechos fundamentales. Dos aspectos esenciales lo demuestran. En primer lugar, la trascendencia del ámbito propio de los derechos individuales hacia el aparato organizativo del Estado, donde este tiene sentido mediante instrumentos enfocados a la realización de tales derechos (dimensión objetiva). En segundo lugar, la existencia de acciones eficaces para la protección inmediata de esos derechos frente a los excesos de las autoridades (dimensión subjetiva). Pero, los derechos fundamentales deben cumplir tres atributos: 1) conexión directa con los principios constitucionales; 2) eficacia directa; y 3) contenido esencial (Sentencia T-406/92, 1992).

Para determinar la adecuada aplicación del derecho material en casación, resulta imprescindible examinar la axiología de la Constitución Política (año) que nos rige. Al respecto, Loewenstein (1979) clasifica las constituciones desde tres perspectivas distintas. En primer lugar, están las constituciones normativas, aquellas en las cuales sus regulaciones alcanzan un mayor grado de efectividad. En segundo lugar, se encuentran las constituciones nominalísticas, que existen de nombre porque sus propósitos o programas no se cumplen efectivamente. Por último, están las constituciones semánticas, que tienen por finalidad establecer procedimientos para perpetuar a individuos o ciertos grupos en el poder (Loewenstein, 1979, pp. 217-219).

Con tal propósito, Alexy (2002) asegura que la categoría superior de los derechos fundamentales enlistados por las constituciones democráticas vincula por igual a los órganos legislativo, ejecutivo y judicial. Por consiguiente, en caso de ambigüedades en la interpretación de la ley, el juzgador ponderará, en el caso concreto, el impacto sobre los derechos fundamentales para evitar al máximo que los mismos puedan 
resultar lesionados con su decisión (Alexy, 2002, pp. 34-35). De esta manera, se plantea un sistema jurídico en el que la validez jurídica, moral y social de la norma se apoya en la intangibilidad de los derechos fundamentales institucionalizados.

Por su parte, Habermas, citado por Mejía (2009, p. 70), confronta los modelos normativos liberal-burgués y el republicano con su lectura de los derechos fundamentales. El filósofo alemán opta por un modelo identificado con el segundo, que agrupa una teoría de la sociedad o de la acción comunicativa, un patrón de decisión judicial deontológico que involucre justicia para todos -en oposición al axiológicoun paradigma reflexivo del derecho. Por último, adopta un modelo de democracia sólido que propenda por la deliberación y participación de la opinión pública.

Por otro lado, a mediados del siglo pasado, Larenz (1980), al analizar las diversas posturas de la jurisprudencia de valoración o de valores -que sucedió a la jurisprudencia de intereses-, sostuvo que para buscar un orden de valores positivizado, que orientara la hermenéutica del jurista alemán, debía pensarse, en primer lugar, en la ley fundamental. Específicamente, se debía pensar en los derechos fundamentales, en los que se encuentran involucrados ciertos valores superiores, entre ellos, la dignidad humana, la igualdad y el libre desarrollo de la personalidad, respecto de los cuales el Tribunal Constitucional declaró un orden jurídico de valores (Larenz, 1980, p. 144).

De allí que se hayan planteado diferentes métodos hermenéuticos para buscar una solución justa ante los problemas de interpretación de la ley y las posibles lesiones de los derechos subjetivos de las partes. No obstante, hoy ese debate no reviste la mayor trascendencia dada la primacía de los derechos fundamentales, pues si bien el reconocimiento de los derechos subjetivos era un problema ético-filosófico, según se expusiera hace unos treinta años, en los ordenamientos vigentes se encuentra solucionado desde el plano dogmático-jurídico (Alexy, 2007, p. 152).

En efecto, como a partir de 1991 Colombia constitucionalizó las normas penales de derecho sustancial y procesal, la decisión judicial debe orientarse a la protección de los derechos fundamentales del ser humano y la sociedad, junto con las garantías vinculadas a este interés ad-hominem. De esta manera, se supera el Estado represor e inquisidor, para dar lugar a instituciones dinámicas que propendan por la verdad de los hechos judiciales, en un plano de igualdad de oportunidades para las partes (Bustamante y Toro, 2016). Por ello, el debate vigente es meramente interpretativo sobre los límites y extensión de la casación frente a las garantías y derechos fundamentales.

Sin embargo, es de reconocer que el control de legitimidad constitucional de la casación se vuelve complejo cuando la función de la Corte Suprema no se reduce a la nomofilaquia y trasciende a errores de actividad que originan la invalidez del proceso, o mayor aun, cuando por vía de la casación se realiza el reexamen de los hechos. De todas formas, más allá de tales complejidades, lo cierto es que, de permitirse 
este control por parte del Tribunal de Casación, amén de la tutela judicial efectiva, se garantizaría la realización de la tan proclamada justicia material, que controle al máximo el arbitrio de los jueces y, por ende, la aleatoriedad judicial.

\subsection{Perspectiva axiológica de la casación}

A pesar de la protección preferente de los derechos materiales -en los que se encuentran los derechos subjetivos-, la Constitución Política de 1991 no estableció en Colombia un tribunal o corte de casación, como aconteció en la Francia posrevolucionaria, ya que las funciones de tribunal de casación fueron atribuidas a la Corte Suprema de Justicia por estar ubicada en el vértice más alto de la pirámide de judicial (Constitución Política, 1991, art. 234-235).

Tal diferenciación, en el plano político y jurídico, marca un efecto muy importante: la actual Corte Suprema es el máximo tribunal de cierre de la jurisdicción ordinaria. Por esta razón, mal podría desprenderse de sus legítimas funciones constitucionales de juez de mérito (actuación del ius litigatoris), por tener asignadas funciones de tribunal de casación (actuación del ius costitutionis), como cuestiona de modo vehemente el profesor Taruffo (2005), quien considera que el control de legitimidad de los hechos y de los vicios in procedendo, representa una especie de tercera instancia y no un verdadero juicio de legitimidad en casación (Taruffo, 2005, pp. 156- 157, 232).

Más allá del aspecto orgánico del nuevo modelo de Estado en la carta política de 1991, lo cierto es que por cuenta de la axiología constitucional que allí se desarrolla, los derechos subjetivos -específicamente los derechos fundamentales- tienen una dimensión superlativa que trasciende la defensa obtusa del principio de legalidad. Con este nació el recurso extraordinario de casación, del que tanto se pregonó en los albores del proceso revolucionario francés, para garantizar la sostenibilidad del pretendido Estado burgués e impedir la intromisión de los jueces en los asuntos legislativos y del gobierno (Montesquieu, 1906, p. 233).

Recuerda Rodríguez (1995) que, en Francia el principio de legalidad, al lado de la separación de poderes - planteado por Montesquieu-, se estableció con la Ley 16 de 1790 y se reafirmó a través del artículo 3 de la Constitución de 1791, al señalar lacónicamente que: "los tribunales no pueden inmiscuirse en el ejercicio del poder legislativo, o suspender la ejecución de las leyes, ni en las funciones administrativas, o citar ante ellos los funcionarios de la administración por razón de sus funciones" (p. 19). Principio acogido fielmente en las constituciones políticas colombianas de los años 1843 (art. 13) y 1886 (art. 57), a diferencia de la del año 1991 (art. 113) que estableció la colaboración armónica institucional. De allí que resulte algo inapropiado aludir al recurso de casación, basado exclusivamente en su etiología nomofiláctica de defensa de la legalidad y de uniformidad de la jurisprudencia. 
Corolario de lo expuesto, al proyectarse la casación como control de legitimidad de la decisión judicial, resultaría más apropiado hablar de la presunción de legitimidad de la sentencia de segunda instancia, en vez de la doble presunción de legalidad y de acierto. Esto le permitiría a la sala especializada de la Corte Suprema de Justicia ejercer a plenitud un control que atienda su carácter de tribunal de casación, de máximo tribunal de mérito y de tribunal constitucional. De esta manera, la sala especializada reconocería en cada caso el carácter prevalente de los derechos fundamentales al debido proceso, a la dignidad, la libertad y la tutela judicial efectiva, acorde con una interpretación constitucional fiel a la diversidad sociocultural de determinados contextos (Zuluaga Jaramillo y Zuluaga Vanegas, 2018, p. 262).

De allí que otro efecto inmediato de esta perspectiva holística, sería el de ajustar las causales, técnicas, los trámites y motivos de inadmisión de la casación a unos criterios que verdaderamente resulten con la naturaleza, función y fines constitucionales del recurso y de los deberes deontológicos del Estado (Constitución Política, año, art. 2).

\subsection{La casación y la efectividad de las garantías procesales}

Pese el reduccionismo al que se ha sometido el principio del debido proceso en la casación, por limitarlo únicamente a los vicios de estructura y de garantías, resulta pertinente analizar si la violación directa e indirecta de la norma sustancial, es decir, si los errores de selección, de subsunción e interpretación de la ley o los defectos fácticos, también implican lesión de la garantía esencial del debido proceso. En el evento de estar transgredido este derecho fundamental -dada su conexidad con la igualdad de trato, el acceso a la justicia, la libertad, la verdad, la reparación, entre otros-, se afianzaría más la tesis de que la casación debería operar como un control de legitimidad (constitucionalidad) contra la sentencia y no como un simple recurso extraordinario que altera la garantía de la doble instancia.

Al revisar la regulación del debido proceso (Constitución Política, año, art. 29), se advierten varios principios y reglas técnicas relativas a la aplicación adecuada de las normas sustantivas: toda persona tiene derecho a un juicio conforme a la ley preexistente a la conducta que se le imputa; al privilegio de la ley favorable; a controvertir las pruebas que se reúnan en su contra; y a la legalidad de la sanción. Por su parte, el artículo 228 constitucional, consagra la carga institucional de lograr la primacía del derecho sustancial en la función pública de impartir justicia.

Acorde con ese enfoque constitucional, existen varias fuentes de derecho objetivo que conciben la aplicación prevalente de la norma sustancial como una de las garantías del debido proceso justo y una correlativa carga deóntica del Estado al impartir justicia. Ahora bien, tal como se indicaba en apartes anteriores, esa norma sustancial no se restringe a la protección del derecho objetivo (norma jurídica), sino que trasciende al resguardo de los derechos fundamentales de las partes involucradas en el proceso 
judicial, quienes reclaman del juzgador la efectividad de los derechos subjetivos que le reconocen las normas de derecho sustancial emanadas del consenso social (Sentencia C-596/00, 2000).

Sobre la casación, la Corte Constitucional precisó que "a través de la prevalencia del derecho sustancial se constitucionalizó la casación como mecanismo para proteger la efectividad material de los derechos fundamentales de las personas" (Sentencia C-880/14, 2014). De contera, el control de legalidad a cargo del tribunal de cierre debe comprenderse en un espectro valorativo que involucre la axiología del actual Estado social de derecho, donde la prevalencia del derecho sustancial sobre el procesal encuentra en la casación el instrumento jurídico más inmediato para la protección de los derechos fundamentales.

Al respecto, la citada sentencia de constitucionalidad indica:

Con el cumplimiento de alguna de las finalidades bastaría para la admisión del recurso por lo que cualquier caso donde se hayan vulnerado los derechos fundamentales de un ciudadano tendrá que ser revisado en sede de casación por la Corte Suprema de Justicia. (Sentencia C-880/14, 2014)

Por esa esencial razón, y dada la primacía de los derechos fundamentales, se impone a la Corte Suprema de Justicia un cambio de perspectiva en cuanto a la admisión del recurso de casación. En este sentido, se busca que prescinda de rigorismos formales y oficiosamente se pronuncie frente a la configuración de vicios de estructura, de garantías, de motivación de la decisión, o incluso ante la violación directa o indirecta de la norma sustancial, connaturales al debido proceso, como pocas veces lo ha asumido con posturas de avanzada (Auto 45.008, 2015). Esto se debe a que la aparente ausencia de vulneración de derechos fundamentales que se supone con la inadmisión del recurso - por cuenta de la inidoneidad sustancial- es un argumento sofístico que comporta limitante al acceso a la justicia (Sentencia SU-635/15, 2015).

Es más, esa perspectiva omnicomprensiva de incorporar como irregularidades del debido proceso las mismas causales de casación (violación directa e indirecta de la ley, nulidad, incongruencia) fue establecida en la Sentencia C-590/05 (2005) de constitucionalidad. Allí, la Corte Constitucional señaló que la acción de tutela procedía contra las decisiones judiciales constitutivas de defecto orgánico, defecto procedimental absoluto, defecto fáctico, defecto material o sustantivo, error inducido, decisión sin motivación, desconocimiento del precedente y violación directa de la constitución (Sentencia SU-490/16, 2016).

\section{CONCLUSIONES}

En el nuevo enfoque, la legalidad viene a ser una regla técnica para la realización del derecho subjetivo de las partes del proceso y no propiamente el objeto exclusivo de la casación. Por tanto, bajo esta orientación, mal podría la casación enfocarse 
prevalentemente a la presunción de legalidad y acierto, que cobija la sentencia de segunda instancia, cuando la aplicación de la ley sustancial preexistente y favorable, junto con la prueba de los hechos, son partes de las garantías del derecho fundamental del debido proceso de los sujetos involucrados en el proceso penal.

En tal sentido, la casación, más que un recurso extraordinario sobre las sentencias de segunda instancia, debe ser un control constitucional que se ejerce sobre la presunción de acierto en la adjudicación de la norma y la valoración de pruebas en la decisión judicial, y la presunción de legitimidad; o debe ser el deber de las autoridades judiciales de mantener un orden justo, de proteger la vida, la libertad, la honra, los bienes, las creencias, los derechos subjetivos y demás derechos de todas las personas.

Para ello, el trámite, la admisión y la resolución de la casación dependerá siempre del enfoque que asuma el legislador y la jurisprudencia, y no necesariamente de la naturaleza del medio de impugnación contra la sentencia de segunda instancia. En esta medida, si la casación se concibe desde la perspectiva de un recurso extraordinario, continuarán los tecnicismos creados -hace más de un siglo- para limitar la eficacia de este. Por otro lado, pensada la casación como medio de control de legitimidad constitucional (protectora de derechos fundamentales), la Corte Suprema como tribunal de casación deberá revisar de fondo los cuestionamientos contra las sentencias de segunda instancia, aunque no se cumplan las exigencias de técnica exigidas en la actualidad para derruir la presunción de legalidad.

Pese al avance legislativo de concebir la casación penal como control constitucional, su trámite y decisión quedaron sujetos a la rigurosidad de tecnicismos que desde hace más de un siglo se han aplicado al recurso extraordinario para la defensa del derecho objetivo (norma sustancial). Con lo cual, se advierte una evidente barrera, en la que el control de la sentencia de segunda instancia se encuentra condicionado a que el interesado cumpla con una rigurosa carga de exigencias técnicas, sin las cuales no es posible admitir la demanda para su estudio.

Esa gran distancia entre el enfoque de la casación desde sus dos perspectivas, bien como un recurso extraordinario o como control de legitimidad constitucional, tiene impacto directo en la efectividad de los derechos fundamentales y el orden justo que pregonan el preámbulo y los artículos 2 y 85 de nuestra carta política.

De concebirse la casación como control de legitimidad constitucional, de la sentencia de segunda instancia se derivarían consecuencias importantes en lo que respecta a las causales, técnicas, el trámite y los motivos de inadmisión de la casación:

En primer lugar, la casación como un control de legitimidad constitucional de las sentencias de segunda instancia, no podrían aludirse deficiencias técnicas para inadmitirse el estudio del recurso. 
En segundo lugar, como un control de legitimidad adverso a la ortodoxa función nomofiláctica, perdería sentido mantener unas causales de casación sujetas a la discrecionalidad de la Corte Suprema, pues la naturaleza de control de legitimidad permitiría ajustar la admisibilidad de la casación. Por ejemplo, a las causales especiales de procedencia de la acción de tutela contra las providencias judiciales señaladas en la Sentencia C-590/05 (2005).

Por último, de agotarse el mencionado control de legitimidad ante la Corte Suprema de Justicia, carecería de objeto acudir -como acontece- a la acción de tutela en contra de las sentencias de segunda instancia, llevando consigo un descongestionamiento de la justicia.

\section{REFERENCIAS}

Ackerman, B. (2011). La Constitución viviente. Filosofía y derecho (1. ${ }^{\text {a }}$ ed.). Marcial Pons Editorial.

Alexy, R. (2002). Derecho y Razón Práctica (1. ${ }^{a}$ ed., vol. 2). Distribuciones Fontamara.

Alexy, R. (2007). Teoría de los derechos fundamentales (2. a ed.). Centro de Estudios Políticos y Constitucionales.

Bacigalupo, E. (1994). La impugnación de los hechos probados en la casación penal y otros estudios (1. a ed.). Ad-Hoc.

Beccaria, C. (2003). De los delitos y de las penas (3. ${ }^{a}$ ed.). Editorial Temis de Bogotá.

Bobbio, N. (2007). El problema del Positivismo Jurídico (1. a ed., vol. 9). Distribuciones Fontamara.

Bustamante, M. y Toro, L. O. (2016). Capítulo III: El estándar de la prueba en el proceso penal ¿El conocimiento más allá de toda duda razonable? Algunas generalidades desde la legislación y la jurisprudencia Colombiana. En D. Agudelo, L. Pabón, L. Toro, M. Bustamante y O. Vargas (coords.), El derecho probatorio y la decisión judicial (pp. 73-106). Sello Editorial Universidad de Medellín.

Calamandrei, P. (1945a). La casación civil -Tomo I- Historia y legislaciones (1. ${ }^{a}$ ed., vol. 1). Editorial Bibliográfica Argentina.

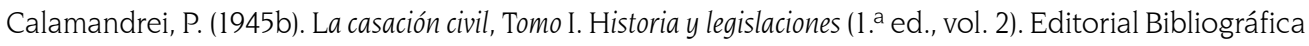
Argentina.

Cappelletti, M. (1974). Proceso, Ideologías, Sociedad. Ediciones Jurídicas Europa-América.

Cappelletti, M. (2007). La Justicia Constitucional. Editorial Porrúa.

Chiovenda, J. (1922). Principios de derecho procesal civil. (J. Casáis y Santaló, trads.). Editorial Reus.

Congreso de la República. (1923, 5 de noviembre). Ley 78 de 1923. Por la cual se establece y reglamenta el recurso de casación en materia criminal. Organización Judicial, Procedimiento Civil y Procedimiento Penal.

Congreso de la República. (1931, 14 de octubre). Ley 105 de 1931.

Congreso de la República. (1931, 14 de noviembre). Ley 118 de 1931. Por la cual se prorroga el término indicado en el artículo 2o de la Ley 11 de 1931 y se dictan algunas disposiciones sobre reformas judiciales. 
Congreso de la república. (2004, 1 de septiembre). Ley 906 de 2004. Código del procedimiento penal [CPP].

Consejo Nacional Constituyente. (1886, 5 de agosto). Artículo 151. Constitución Política de Colombia.

Consejo Nacional Legislativo. (1886, 25 de noviembre). Ley 61 de 1886. Provisional sobre organización y atribuciones del Poder Judicial y el Ministerio Público y algunos procedimientos especiales.

Constitución Política de Colombia [Const]. Artículo 219. 7 de julio de 1991 (Colombia).

Corte Constitucional (1992, 5 de junio). Sentencia T-406/92 (Ciro Angarita Barón, M. P.).

Corte Constitucional (1994, 28 de abril). Sentencia C-215/94 (Fabio Morón Díaz, M. P.).

Corte Constitucional (1995, 9 de febrero). Sentencia C-038/95 (Alejandro Martínez Caballero, M. P.).

Corte Constitucional (1995, 29 de marzo). Sentencia C-140/95 (Vladimiro Naranjo Meza, M. P.).

Corte Constitucional (2000, 24 de mayo). Sentencia C-596/00 (Antonio Barrera Carbonell, M. P.).

Corte Constitucional (2000, 16 de agosto). Sentencia C-1065/00 (Alejandro Martínez Caballero, M. P.).

Corte Constitucional (2001, 28 de febrero). Sentencia C-252/01 (Carlos Gaviria Díaz, M. P.).

Corte Constitucional (2006, 4 de octubre). Sentencia C-820/06 (Marco G. Monroy Cabra, M. P.).

Corte Constitucional (2011, 12 de mayo). Sentencia C-372/11 (Jorge I. Pretelt Chaljub, M. P.).

Corte Constitucional (2013, 30 de octubre). Sentencia C-753/13 (Mauricio González Cuervo, M. P.).

Corte Constitucional (2014, 19 de noviembre). Sentencia C-880/14 (Gloria S. Ortiz Delgado, M. P.).

Corte Constitucional (2015, 7 de octubre). Sentencia SU-635/15 (Jorge I. Pretelt Chaljub, M. P.).

Corte Constitucional (2016, 13 de septiembre). Sentencia SU-490/16 (Gabriel E. Mendoza Martelo, M. P.).

Corte Suprema de Justicia (1982, 22 de julio). Gaceta Judicial 2408, Tomo CLXX (Darío Velásquez

Gaviria, M. P.). https://cortesuprema.gov.co/corte/wp-content/uploads/subpage/GJ/Gaceta\%20 Judicial/GJ\%20CLXX\%20n.\%202408\%20(1982).pdf

Corte Suprema de Justicia (1997, 26 de noviembre). Sentencia de Casación Penal 10094/97 (Jorge Aníbal Gómez Gallego, M. P.).

Corte Suprema de Justicia (2000, 31 de mayo). Auto de Casación Penal 15948 (Nilson Pinilla Pinilla, M. P.).

Corte Suprema de Justicia (2000, 19 de diciembre). Auto de Casación Penal 16054 (Álvaro O. Pérez Pinzón, M. P.).

Corte Suprema de Justicia (2000, 19 de diciembre). Auto de Casación Penal 16776 (Jorge E. Córdoba Poveda, M. P.).

Corte Suprema de Justicia (2005, 16 de febrero). Auto de Casación Penal 20666 (Álvaro O. Pérez Pinzón, M. P.).

Corte Suprema de Justicia (2005, 12 de diciembre). Auto de Casación Penal 24322 (Marina Pulido de Barón, M. P.).

Corte Suprema de Justicia (2005, 20 de octubre). Auto de Casación Penal 24026 (Mauro Solarte Portilla, M. P.). 
Corte Suprema de Justicia (2007, 3 de octubre). Auto de Casación Penal 28387 (Sigifredo Espinosa Pérez, M. P.).

Corte Suprema de Justicia (2010, 21 de julio). Auto de Casación Penal 33170 (José L. Bustos Martínez, M. P.).

Corte Suprema de Justicia (2011, 19 de enero). Auto de Casación Penal 30073 (Fernando Alberto Castro Caballero, M. P.).

Corte Suprema de Justicia (2011, 23 de febrero). Auto de Casación Penal 34948 (Augusto J. Ibáñez Guzmán, M. P.).

Corte Suprema de Justicia (2011, 10 de junio). Auto de Casación Penal 36053 (Julio E., Socha Salamanca, M. P.).

Corte Suprema de Justicia (2015, 16 de diciembre). Auto de Casación Penal 45.008 (Eugenio Fernández Carlier, M. P.).

Corte Suprema de Justicia (2020, 29 de enero). Auto de Casación Penal AP-293 (José F. Acuña Vizcaya, M. P.).

Corte Suprema de Justicia (2020, 26 de febrero). Auto de Casación Penal AP-648 (Eyder Patiño Cabrera, M. P.).

Devis, H. (1966). Nociones Generales de Derecho Procesal Civil. Editorial Aguilar.

Ferrajoli, L. (2004). Derechos y garantías. La ley del más débil (4. ${ }^{\text {a }}$ ed.). Editorial Trotta.

Fioravanti, M. (2000). Los derechos fundamentales (3. ${ }^{a}$ ed.). Editorial Trotta.

Goldschmidt, W. (1987). Introducción filosófica al derecho. La teoría trialista del mundo jurídico y sus horizontes (6. ${ }^{\text {a }}$ ed., vol. 5). Ediciones Depalma.

Larenz, K. (1980). Metodología de la ciencia del derecho (2. ${ }^{\text {a }}$ ed.). Ariel.

Loewenstein, K. (1979). Teoría de la Constitución (2. a ed., vol. 1). Ariel.

Martínez, A. (2010). Recurso de casación y de revisión penal. Control de la presunción de inocencia (1. a ed.). Tirant Lo Blanch.

Mejía, O. (2009). Estatuto epistemológico de la filosofía del derecho contemporáneo. Grupo Editorial Ibáñez.

Moreno, L. (2015). La casación en la Ley 906 de 2004. Teoría y Práctica Bajo la Nueva Orientación Constitucional. Ediciones Nueva Jurídica.

Montesquieu (1906). El espíritu de las leyes - Tomo I (1. a ed.). Librería General de Victoriano Suárez.

Presidente de la República de Colombia. (1970, 4 de agosto). Decreto 1345 de 1970. Por el cual se codifican las normas sobre Procedimiento Penal.

Presidente de la República de Colombia. (1971, 27 de marzo). Decreto 409 de 1971. Por el cual se introducen reformas al Código de Procedimiento Penal y se codifican todas sus normas.

Presidente de la República de Colombia. (1987, 13 de enero). Decreto 50 de 1987. Código del Procedimiento Penal [CPP].

Presidente de la República de Colombia. (1991, 30 de noviembre). Decreto 2700 de 1991. Por el cual se expiden las normas de Procedimiento Penal. 
Ramírez, Y. (2011). Casación Penal (1. a ed.). Editorial Leyer.

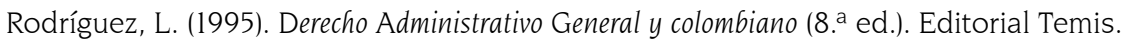

Rossanvallon, P. (2015). El buen gobierno (1. a ed.). Ediciones Manantial SRL de Buenos Aires.

Taruffo, M. (2005). El vértice ambiguo. Ensayos sobre la Casación civil (1. ${ }^{\text {a }}$ ed.). Palestra editores.

Tolosa, L. A. (2005). Teoría y técnica de casación (1. ${ }^{a}$ ed.). Ediciones Doctrina y Ley.

Troncoso, J. (2017) La casación como control de legitimidad de las sentencias de segunda instancia en Colombia [tesis de maestría no publicada, Universidad Sergio Arboleda].

Zuluaga Jaramillo, A. F. y Zuluaga Vanegas, S. (2018). Funciones de la ideología en la hermenéutica constitucional. Una mirada desde la filosofía de Paul Ricoeur. Opinión Jurídica, 17(33), 255-275. https://doi.org/10.22395/ojum.v17n33al1 